\title{
A MODA E AS MULHERES: AS PRÁTICAS DE COSTURA E O TRABALHO FEMININO NO BRASIL NOS ANOS 1950 E 1960
}

DOI: http://dx.doi.org/10.1590/2236-3459/60209

\author{
Débora Russi Frasquete \\ Università luav di Venezia (IUAV), Itália
}

Ivana Guilherme Simili

Universidade Estadual de Maringá (UEM), Brasil

$\cos 80$

\begin{abstract}
Resumo
A construção dos aprendizados femininos com os tecidos, linhas e máquinas de costura, é analisada neste texto por meio das informações disseminadas por dois gêneros textuais diversos na transmissão de conhecimentos. O primeiro é o curso de corte e costura intitulado Método Vogue associado à Escola de Corte e Costura São Paulo e de autoria de Antonio Campagnolli, que mesmo com lacunas documentais sobre a totalidade de publicações, está no volume analisado em sua décima nona edição. Este material didático instrumentalizou milhares de mulheres à prática do corte e costura com seus volumes de cursos por correspondência que, juntamente ao Instituto Universal Brasileiro, dinamizou o ensino com a sua propagação ao interior do país por meio dos Correios. O segundo é Jornal das Moças, uma revista carioca produzida pela Editora Jornal das Moças Ltda. Um periódico semanal circulado entre os anos de 1914 a 1961 e que em suas páginas jovens e senhoras encontravam orientações sobre moda, beleza, costura, casa, culinária e cuidados com os filhos. Ambas as fontes são suportes na compreensão da relação feminina com a prática de corte e costura e neste intuito circunscrevemos a análise aos anos 1950 e 1960, pelos investimentos presentes neste período na divulgação do ensino desse ofício. Com o objetivo de compreender as concepções que nesse período relacionaram o ensino do corte e costura às mulheres, o texto é dividido em três partes que exploram o corte e costura associado à imagem feminina, sua difusão midiática e sua contribuição para a educação e para o trabalho feminino profissional e doméstico.

Palavras-chave: educação e trabalho, corte e costura, moda, mulheres.
\end{abstract}

\section{FASHION AND WOMEN: THE PRACTICE OF SEWING AND THE FEMININE WORK IN BRAZIL IN THE YEARS 1950 AND 1960}

\begin{abstract}
The construction of Brazilian female learning with fabrics, threads and sewing machines is analyze in this text through two different textual genres in knowledge transmission: a didactic book and a Magazine. The first is Método Vogue associated with the School of Pattern making and Sewing "São Paulo" and authored by Antonio Campagnolli. It is unknown how much it was published, but in 1967 it is in the nineteenth edition. This didactic material enabled thousands of women to practice pattern making and sewing with their correspondence courses that supported by Instituto Universal Brasileiro, stimulated sewing learning with its propagation to the
\end{abstract}


interior of Brazil through the Post Office. The second is Jornal das Moças, a weekly Brazilian magazine published by Editora Jornal das Moças Ltda in Rio de Janeiro. Between the years 1914 to 1961 in its pages women of all ages found orientations on diverse aspects, including fashion and sewing. Both sources are support to understand the female relationship with the practice of pattern making and sewing: the book to understand the teaching of that craft to women and the magazine as support of the female image dissemination associated to sewing. In this intention, we limited the analysis to the 1950's and 1960's because of the government support on spread the teaching of that craft. The text divided into three parts explore the association of pattern making and seam with feminine image; its media diffusion and its contribution to the education of women to the professional and domestic labor.

Keywords: education and work, cutting and sewing, fashion, female.

\title{
MODA Y MUJERES: LA PRÁCTICA DE COSER Y EL TRABAJO FEMENINO EN BRASIL EN LOS AÑOS 1950 Y 1960
}

\begin{abstract}
Resumen
La construcción del aprendizaje femenino en coser, se analiza en este texto por medio de la información difundida por dos géneros diferentes en la transmisión de conocimientos. Lo primero es el material didáctico de cortar y coser titulado Método Vogue asociado a la Escuela de Cortar y Coser São Paulo y escrito por Antonio Campagnolli que incluso con lagunas documentales respecto a la totalidad de publicaciones, está el volumen analizado en su XIX edición. Este material didáctico ha instrumentalizado miles de mujeres a la práctica del cortar y coser en Brasil con sus volúmenes de cursos por correspondencia que adjunto al Instituto Universal Brasileiro, ha propagado la enseñanza al interior del país a través de los Correos. El segundo es una revista titulada Jornal das Moças producida por la Editora Jornal das Moças Ltda. Un boletín semanal que ha circulado entre los años 1914-1961 y que en sus páginas jóvenes y señoras encuentran directrices para moda, belleza, coser, jardinería, cocina y cuidado con los hijos. Ambas fuentes son soportes en la comprensión de la relación de las mujeres con la práctica del cortar y coser y en este orden circunscribimos el análisis a los años 1950 y 1960, por las inversiones en este período en la difusión de esta enseñanza. Con el fin de entender los conceptos que en ese período han relacionado la educación del coser a las mujeres, el texto se divide en tres partes que se componen del cortar y coser asociado a la imagen femenina, su difusión en los medios de comunicación y su contribución a la educación y trabajo profesional y doméstico femenino. Palabras clave: educación y trabajo, cortar y coser, moda, mujeres.
\end{abstract}

\section{MODE ET FEMMES: LA PRATIQUE DE LA COUTURE ET LE TRAVAIL FÉMININ AU BRÉSIL DANS LES ANNEES 1950 ET 1960}

\begin{abstract}
Résumé
La construction des apprentissages féminins avec tissu, fil et machines à coudre, est analysée dans cet article à travers les informations diffusées par deux genres différents dans la transmission des connaissances. La première est la course de coupe et couture intitulé Método Vogue associé à l'École de Coupe et Couture São Paulo et rédigé par Antonio Campagnolli que même avec des lacunes documentaires sur toutes les publications, est le volume analysé dans sa dix-neuvième édition. Cette matériel didactique a instrumentalisées des milliers de femmes à la pratique de coupe et couture avec leurs volumes de cours par correspondance que ensemble àl' Instituto Universal Brasileiro, rationalisé l'enseignement avec sa propagation à l'intérieur du Brésil par l'intermédiaire du bureau de poste. Le second est Jornal das Moças, une Magazine brésilien produit par Editora Jornal das Moças Ltda. Un bulletin d'information hebdomadaire distribué entre les années 1914-1961 où les jeunes et les dames trouvaient les directrices sur la mode, la beauté, la couture, le jardinage, la cuisine et la garde des enfants. Les deux sources sont des supports pour la compréhension de la relation entre les femmes et le pratique de coupe et couture, dans cet ordre nous circonscrivons l'analyse aux années 1950 et 1960, par des investissements dans cette période dans la diffusion de l'enseignement de ce métier. Afin de comprendre les concepts que liée l'éducation et la couture aux féminine, le texte est divisé en trois parties qui exploitent la coupe et couture associée à l'image féminine, leur diffusion médiatique et sa contribution à l'éducation et à le travail des femmes professionnelles et domestiques.
\end{abstract}

Mots-clés: éducation et travail, coupe et couture, mode, femme. 


\section{Introdução}

$\mathrm{N}$

o início do século XX, as políticas de educação feminina e os discursos de gênero estão na base da história do ensino direcionado às mulheres.

Podemos afirmar que, as concepções sexistas de espaços de atuação, de papéis e de destinos sociais diferenciados para homens e mulheres que surgem no final do século XIX, fez que, no século XX, se observassem algumas permanências e mudanças nas maneiras de conceber e de educar os/as meninos/as, os/as jovens, as/os senhores/as.

Como bem mostrou Perrot (2005), no final do século XIX, as concepções biologizantes e essencialistas pautadas na existência de diferenças entre homens e mulheres disseminam-se pelas instâncias e esferas de poder e de controle sobre as pessoas. A constituição de espaços sexuados transforma o mundo público em masculino e o privado, em feminino. A separação das esferas com suporte nas características concebidas como naturais do homem para a razão, para os negócios da política, enfim para a vida pública e, para a mulher, os sentimentos, a docilidade, a delicadeza entre outros adjetivos, fez com que o mundo privado da casa e tudo o que lhe dizia respeito, fosse transformado em seu "lugar no mundo". Estas representações são fabricadas e difundidas pela vida social, penetrando e educando as subjetividades e sensibilidades das pessoas.

As concepções e as representações sexistas, em voga entre final dos séculos XIX e início do $\mathrm{XX}$, foram incorporadas e traduzidas pelos projetos pedagógicos de ensino para as mulheres e configuram a história da educação feminina. No período, os projetos educacionais visando à formação das mulheres orientaram-se pela concepção de que elas deviam ser preparadas para o lar, para o desempenho de funções entendidas pelos homens como apropriadas ao feminino, quais sejam: o cuidado do marido, dos filhos e o desenvolvimento de habilidades e competências que estavam relacionadas à posição que ocupavam na família e na sociedade, nas quais deveriam comportar-se de acordo com princípios específicos como a cooperação com o outro sexo, a obediência, o altruísmo, a docilidade entre outras. Nos projetos e nas práticas pedagógicas dos anos 1930 e 1940, o ensino feminino é direcionado para a formação das mulheres para o desempenho das funções de educadoras dos filhos da nação, de formadoras dos futuros cidadãos, dos homens da nação. (LOPES, 1991).

Em 1937, o projeto pedagógico equivalente ao ensino médio e secundário na educação das mulheres - jovens entre 12 e 18 anos - implementado pelo Ministro da Educação em exercício Gustavo Capanema - havia coroado algumas concepções em voga com relação ao tipo de formação a lhes ser dada com a inclusão da "economia doméstica", de aulas de higiene, de alimentos, de vestuário, da habitação, com aulas de enfermagem para que aprendessem a cuidar dos doentes, aulas de culinária voltadas para o preparo de alimentos, a ornamentação e regras de etiqueta, aulas de sociologia educacional voltada para a orientação de questões relacionadas à família, à Igreja e aos problemas sociais como o pauperismo. (SCHWARTZMAN; BOMENY; COSTA, 2000, p. 126).

Permanências e mudanças nos investimentos governamentais na educação das mulheres são observadas durante a Segunda Guerra Mundial. Os cursos para a formação das voluntárias, criados pela Legião Brasileira de Assistência entre setembro e dezembro de 1942, nos primórdios da entrada do país no conflito mundial e da organização da instituição, indicam a transformação dos conteúdos da educação formal em "especialidades" para a formação e composição de estilos voluntários, fazendo com que 
elas prosseguissem no aprendizado escolar, porque o público que passou a frequentá-los era composto por jovens com idade entre 18 e 21 anos e pertencente aos segmentos médios e da elite da população feminina carioca. (SIMILI, 2008).

Entre as especialidades da educação formal, uma delas ganha destaque, as salas de costura, por meio das quais, as habilidades e os conhecimentos relativos ao vestuário, um aprendizado da grade de ensino, são remodelados levando as mulheres a produzirem roupas para os soldados mobilizados pelo conflito mundial. As costureiras da Legião Brasileira de Assistência reforçam os princípios do trabalho doméstico e privado para a vida pública e política originada pela participação do país no conflito mundial. (SIMILI, 2008).

Ao modelo de feminino e de feminilidade de "costurar e produzir roupas", a imprensa dava a sua contribuição. Nos anos 1950 e 1960, embora muitas mudanças sejam observadas no cenário nacional e na educação das mulheres, as quais foram geradas pela maior escolarização dos segmentos femininos, pelo ingresso delas no mercado de trabalho entre outros aspectos que alteram as percepções e as relações entre os gêneros, o modelo feminino e de feminilidade dominante era a da esposa e mãe e/ou da mulher dedicada ao lar. Novos tempos, novas exigências feitas às mulheres sobre como usar os conhecimentos de costura em benefício próprio e da família. As relações das mulheres com o mercado de consumo e de produção de vestuário ganham novos matizes. A imprensa, como educadora das práticas de costura permanece como veículo de comunicação e de ensinamentos sobre como "cortar e costurar". O corte e a costura adquire, assim, novos sentidos, inclusive e particularmente, pelos cursos presenciais e a distância, caso do Instituto Universal Brasileiro e da Escola de Corte e Costura São Paulo responsável pelo Método Vogue.

Pode-se dizer que o papel da mulher brasileira esteve influenciado pelo discurso ideológico da "costura" como "coisa de mulher", que permeado por ideias educacionais rígidas reafirmavam os papéis indissociáveis de mãe, esposa e dona-de-casa exemplar, a quem a atuação profissional consistia em trabalhos que poderiam ser realizados no seio do lar, como maneira de servir aos filhos e marido e em último caso, de complementar a renda da família. Partindo dessa ideia às mulheres eram destinados serviços como costurar e bordar, conhecidos como prendas domésticas e que eram práticas ensinadas tanto de mãe para filha, como por cursos presenciais ou por correspondência, tendo sido amplamente difundidas pelas revistas femininas veiculadas no período, que apresentavam em seus fascículos cadernos com dicas de moda e de construção de moldes. Como escreve Mendonça (2013, p. 2) a forma como a moda rege a imprensa dirigida para mulheres vai muito além da representação de roupas, pois passa pelo recorte das pautas, pelo estilo de vida que é sugerido, pela beleza, pela casa e toda uma ideia de feminilidade, focada na gerência das aparências.

Isto posto, o artigo tem por objetivo examinar a construção dos aprendizados das jovens e senhoras com os tecidos, linhas e as máquinas de costura e a sua importância para o mercado de trabalho feminino, por meio da análise das informações disseminadas pelo Método Vogue e a sua compreensão como documento de história da moda, e pela revista Jornal das Moças, como suporte documental para a análise do primeiro artefato de ensino. O Método Vogue de autoria de Antonio Campagnolli publicado pela Escola de Corte e Costura São Paulo, ainda que um material de cunho pedagógico, apresenta diversas páginas de incentivo ao estudo do ofício de corte e costura e a sua autopromoção, que possibilita a análise da imagem feminina nas décadas de 1950 e 1960, principalmente 
quando à essa imagem está associada a visão masculina daquele que o escreveu. $\mathrm{O}$ método foi um dos meios do período, pelos quais há a reprodução do modelo dominante, o masculino, como hegemônico na prescrição das condutas femininas. Nas linhas e entrelinhas, as páginas do curso por correspondência trazem também as marcas do olhar dos homens sobre as mulheres.

Nesse sentido, ambas as fontes tratavam de "temas cujos referenciais obrigatórios eram os papeis domésticos tradicionalmente reservados às mulheres e as características consideradas "próprias de mulher", englobadas na ideia de "feminilidade" que então se difundia" (PINSKY, 2014, p.23). Nesse sentido, disseminavam a aprendizagem tanto para o consumo de moda quanto para a profissionalização feminina para o mercado de produção de roupas. O Jornal das Moças (1914-1965), revista carioca produzida pela Editora Jornal das Moças Ltda., era um periódico semanal que teve seu primeiro número publicado em maio de 1914, permanecendo no mercado até dezembro de 1961 (SANTOS, 2011). A revista de maior vendagem nas décadas de 1940-1950, transforma-se em exemplar suporte à compreensão da pedagogia de gênero presente no Método Vogue, pois eram em suas páginas que as jovens e senhoras encontravam orientações sobre moda, beleza, casa, culinária e cuidados com os filhos (LUCA, 2012, p. 448), complementando a educação feminina no período.

Circunscrevemos a análise aos anos 1950 e 1960, por considerarmos que no período os investimentos no ensino de corte e costura e bordados sofrem mudanças significativas, redimensionando, assim, os conhecimentos, as formas de trabalho e os usos das roupas. Modernização da moda que faz emergir novas estratégias de ensino, com métodos específicos que se associam aos antigos, os quais educam as mulheres com os ensinamentos sobre como fazer roupas. Referidas estratégias, transformam e produzem sentidos para os conceitos e as práticas de costura e os conhecimentos de moda.

A fim de identificar esse cenário de mudanças nas percepções e nos conhecimentos de moda, os fascículos de cursos de corte e costura por correspondência, como o Método Vogue e aquele desenvolvido pelo Jornal das Moças sobre "costura e bordado", contribuem ao campo de estudos da educação técnica brasileira e de seus respectivos impactos na cultura do período. Tanto os cursos por correspondência, como as revistas, visavam difundir o ensino do corte e costura, sendo direcionadas a mesma mulher: doméstica, que lê romances, aprende a se vestir com elegância e que costura e cozinha para a família, entretanto não descartavam a opção do ofício como trabalho feminino, como profissão.

\section{A imagem feminina e o corte e costura}

A "moda feminina sempre é um estatuto sobre os papéis das mulheres e sobre como estes são ou deveriam ser desempenhados" (CRANE, 2011, p. 209). Logo, a cultura dos gêneros e da moda que permeava as relações das mães com as filhas, das jovens com o casamento e com a maternidade constitui-se no caminho para entendermos os papéis sociais prescritos às mulheres e como estes foram transmitidos, assimilados, incorporados em suas vidas e performances, visto que "as imagens femininas, historicamente e culturalmente, se adaptaram aos papéis sociais que lhes foram tributados, a partir das representações sociais provenientes de um sistema patriarcal” (SCHOLL, 2012, p. 36).

$\mathrm{Na}$ primeira metade do século $\mathrm{XX}$, a educação das meninas envolvia os 
aprendizados dos trabalhos manuais de costurar e de bordar, transmitidos de mãe para filha, como meio de prepará-la para o casamento, concebido como destino "natural da mulher" (ARENDT, 2012). Bordar os lençóis, as toalhas para o enxoval; aprender corte e costura para fazer roupas para si e, no futuro, como mulheres casadas e mães, vestirem e decorarem a casa, montarem o guarda-roupa da família - com vestimentas para o marido e os/as filhos/as, eram noções que modelavam as subjetividades das meninas, das jovens e das senhoras como saberes e fazeres compartilhados socialmente.

De certa forma, os aprendizados neste período são construídos por meio de tentativas, erros e acertos, $\mathrm{O}$ aproveitamento de saberes e fazeres da costura, ou dos trabalhos com as agulhas, contribuem na construção de uma imagem feminina idealizada. Essa representação da mulher fica evidente nas páginas do famoso Método Vogue, que como um curso profissionalizante de corte e costura a distância, se comunica com as mulheres da década de1960 com citações como: "Quem julga as imperfeições femininas são os olhos masculinos" (CAMPAGNOLLI, 1967, p. 48) ou ainda, "as condições da vida moderna atiram a mulher para a luta! Procure garantir o futuro de suas filhas, dando-lhes um curso de Corte e Costura por correspondência [...]". (CAMPAGNOLLI, 1967, p. 10).

Frases de efeito como as citadas acima, tinham o intuito original de persuadir as mulheres do período a estudarem corte e costura, porém, como a educação dos filhas em termos gerais era supervisionada e controlada pelo pai e após o casamento suas responsabilidades eram transferidas ao marido, é visível na publicidade inclusive a tentativa de persuadir esses homens à compra do curso de corte e costura, e nesse sentido, como aquele que escreve também é homem, reconhece-se a visão masculina a respeito das mulheres na década de 1960. Considerando esse argumento, por meio da análise das publicidades veiculadas internamente às páginas do curso de corte e costura é possível identificar interpretações a respeito do papel da mulher, como era vista, e o que era considerado importante aos seus olhos e aos da sociedade patriarcal nesse período, como mostra o exemplo:

A vida sobre a terra é incerta. Precisamos nos preparar para o que vier. Os pais não vivem sempre e eles devem preparar o dote de suas filhas dando-lhes uma profissão honrosa, garantindo o futuro da vida de suas filhas, assim como os esposos o de suas esposas, pois não sabem o dia de amanhã e as vezes o braço forte falta e é preciso o fraco movimentar-se. Assim sendo, poderão ganhar a vida em seus próprios lares sem sofrerem muitas amarguras, que na maioria das vezes a vida nos traz. (CAMPAGNOLLI, 1967, p. 16).

Para a sociedade da época, docilidade, meiguice, serenidade e resignação eram características femininas e assim, a imagem da mulher era associada ao braço fraco, aquele a que apenas era destinado os trabalhos simples e leves, considerados de menor importância. A escolaridade feminina neste período era muito básica. Enquanto os meninos continuavam seus estudos até galgarem diploma universitário, "um número significativo de jovens mulheres até os anos 1950 mal conseguia concluir o curso secundário. As que seguiram em frente nos estudos quase sempre optavam pelas carreiras profissionais consideradas femininas. (AREND, 2012, p. 72).

Nesse sentido os cursos de corte e costura eram opção para grande parte das mulheres. Como é divulgado pelo Método Vogue: "As senhoras de qualquer Estado do Brasil, que não possam vir às aulas fazer o curso individual, poderão fazê-lo perfeitamente 
por CORRESPONDÊNCIA, a domicílio, bastando para isso que tenha instrução primária" (CAMPAGNOLLI, 1967, p. 48). Está escrito inclusive: "Não necessita V. S. de nenhuma classe de preparo especial para fazer o curso completo e conseguir logo um Diploma de Modista, Contra-Mestre, ou de Professora, que são provas dos conhecimentos adquiridos" (CAMPAGNOLLI, 1967, p. 17). Essas citações enfatizam a possibilidade de um ofício indispensável para as mulheres desse período, e que era realizável mesmo com pouca instrução.

Termos como a mulher "moderna" ou a mulher de "hoje" são encontrados nas diversas formas de escrita da época, seja em revistas como Claudia, lançada em 1961 pela Editora Abril ou nos fascículos dos cursos de corte e costura por correspondência como os do Método Vogue, que representando o ideal da nova mulher, fruto do segundo pós-guerra, o difundia por todo o Brasil, da capital aos lugares mais distantes. Como os grandes cursos presenciais ocorriam nas capitais, os cursos por correspondência tinham o objetivo de atingir as mulheres do interior do país. Essa afirmação se confirma nas páginas do Método Vogue: "No desejo de contribuir para o bem-estar de nossas patrícias do interior, organizamos este curso por correspondência". (CAMPAGNOLLI, 1967, p. 24).

Assim sendo, as mulheres do interior, mesmo distantes das movimentações concentradas em sua maioria nas capitais, passam a ter acesso, tanto a essa representação feminina presente nas revistas e cursos por correspondência, como a uma nova forma de ensino de corte e costura, a distância e em parceria com os Correios. Com isso, foi possível suprir a divulgada necessidade de todas as mulheres, independente do lugar em que habitassem, aprenderem este ofício, tão estimado para a sociedade da época e que faria com que essas fossem ainda mais femininas:

Para a mulher de hoje, o aprendizado de corte e costura é uma necessidade pelas seguintes vantagens: A) - Não gastando com costureiras, poderá gastar consigo mesmo e assim andar sempre bem trajada. B) - Apresentando-se sempre bem vestida, será mais considerada pelas suas amigas, e mais apreciada pelos homens de bom gôsto. C) - Poderá abrir um atelier de costura, ganhando honestamente, garantindo o seu futuro e de seus filhos. D) - Não se achará nunca diante das desgraças que a miséria aconselha às moças que ficam desamparadas no mundo. (CAMPAGNOLLI, 1967, p. 24).

Esse ideal de feminilidade abrangia estar sempre bem vestida, e com isso ganhar maior consideração na sociedade como um todo, associando $o$ ato do bem vestir a causa de inveja às outras mulheres e desejo aos homens, assim como também a ideia do ganho de dinheiro honesto e ao fato que ao aprender o ofício da costura estaria se preparando para os infortúnios que possam advir. Nesse sentido a propaganda objetiva persuadir desde as moças jovens e solteiras, a ganhar admiração masculina, como as mulheres casadas em fazer economia e estar preparada para atuar profissionalmente caso quisessem ou necessitassem. Assim, as práticas de costura do período estavam intimamente relacionadas a imagem feminina, tanto das moças solteiras como das mulheres casadas, $\mathrm{e}$ contribuíam para o seu desenvolvimento de forma recíproca. Como escreve Campagnolli para o Método Vogue, os resultados de seus cursos por correspondência o animavam "sempre a prosseguir na luta, para o embelezamento da plástica feminina e na educação profissional da mulher do nosso querido Brasil". (CAMPAGNOLLI, 1967, p. 20). 


\section{A difusão do ensino de corte e costura}

Nas transmissões de saberes e fazeres relativos às roupas ou no projeto de educação feminina para a moda, os jornais e as revistas da época davam a sua contribuição. As revistas femininas constituíam-se em um dos principais passatempos femininos. Muitas das publicações literárias e periódicas, difundiam regras de etiqueta e noções de elegância que seriam provavelmente colocadas em prática na vida adulta ao lado do futuro esposo (AREND, 2012). No Jornal das Moças, as mulheres encontravam "receitas de trabalhos manuais", com os desenhos chamados de "riscos", de frutas e flores para serem copiados e bordados nos panos de cozinha, nas toalhas de mesa; de borboletas, laços e pombinhas, um símbolo religioso da paz e da felicidade conjugal, para serem impressos nas roupas de cama. Moldes de roupas, conforme a estação e as tendências da moda compunham os materiais didático-pedagógicos disponibilizados às mulheres, atualizando-as e mantendo-as informadas sobre como fazer, o que vestir e como usar os vestidos e os acessórios.

A relação das mulheres com o mercado de moda se abre portanto a duas faces: a do consumo e a da produção, nas quais essas estiveram envolvidas. Fazer roupa para se vestir e fazer roupa para sobreviver, duas faces visíveis no mercado de produção e de consumo nos anos 1950 e 1960. Com o mercado da moda brasileira em expansão no período, havia o incentivo ao consumo e a produção de moda pelas mulheres, e para tanto revistas como Jornal das Moças e Manequim davam grande contribuição. Deve-se ter em vista que, na teoria do consumo, o que interessa é que "[...] as chamadas necessidades básicas são inventadas e sustentadas na cultura" (DOUGLAS; ISHERWOOD, 2009, p. 15 in FERREIRA, 2010, p. 5) e dessa forma o processo de difusão e propagação do consumo do que seria considerado necessidade básica, se fundamenta principalmente por questões culturais enraizadas na sociedade. Nesse sentido, nota-se que uma dessas necessidades difundidas pelas mídias do período como básica à qualquer mulher era o cortar e costurar, considerado indispensável à imagem feminina e de feminilidade. Esse incentivo à costura entrelaçado à imagem feminina foi reforçado, por exemplo, na década de 1950, nas capas da revista Jornal das Moças, como a edição de 15 de outubro de 1959.

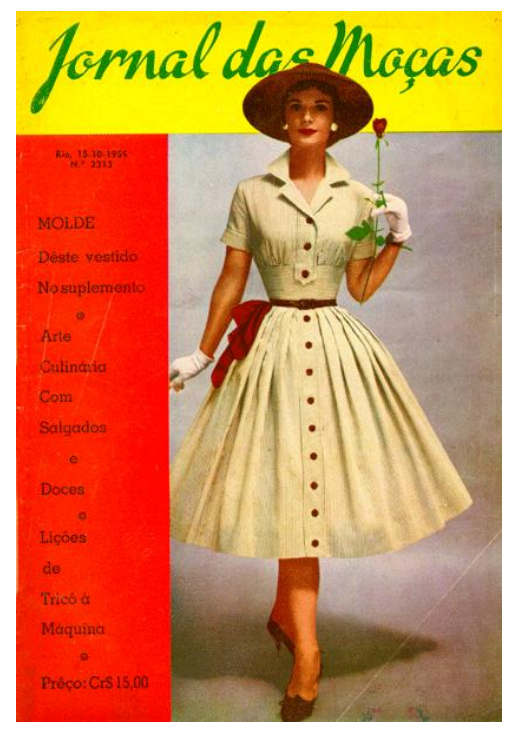

Figura 1 - Jornal das Moças № 2313, de 1959.

Fonte: Biblioteca Nacional Digital Brasil. 
Este exemplar da revista apresenta na capa indícios da imagem da mulher associada a extrema feminilidade, bem trajada, com postura impecável e cintura marcada associada a uma delicada rosa, símbolos da feminilidade, ou da construção de uma identidade feminina que pode ser chamada de dominante na década de 1950. A edição evidencia também a tentativa de popularização da moda, muito forte nesse período, com lições de tricô à máquina e ilustrações dos últimos modelos para serem reproduzidos/copiados, principalmente com a inclusão do molde dos modelos no encarte da revista, que difundiu a ideia do corte e costura sem grandes dificuldades.

Assim como essa, outras revistas marcam um período de difusão do corte e costura e da moda, com a disponibilização dos encartes de moldes de modelos para que as mulheres pudessem confeccioná-los em casa, sem tanto ônus. A revista Manequim lançada em 1959 pela Editora Abril, como a primeira revista brasileira dedicada inteiramente à moda é um marco, visto que trazia "moldes e visava um público especializado: costureiras e mulheres que costuravam em casa. A pioneira Manequim desempenhou um papel muito importante no desenvolvimento da indústria de confecção" (BUITONI, 2009, p. 100). A revista possuía o atrativo de aliar os desenhos à moldes, que explicavam passo a passo 0 processo de confecção da roupa. (LUCA, 2012).

Partindo dessa perspectiva, as revistas tiveram um importante papel para a moda da época, pois disponibilizando os moldes, possibilitava às mulheres o acesso aos modelos apresentados pelas revistas como a última moda, principalmente vinda de Paris, que retratava o conceito de elegância e refinamento disponível às mulheres na década de 1950. Com o objetivo de estimular o corte e costura no período, era facilitada às mulheres a reprodução de modelos descrevendo suas características, qual tecido utilizar, os aviamentos necessários, entre outras informações pertinentes à sua confecção. Unida aos encartes semanais dessas revistas, a ideia de utilizar materiais que houvesse disponível para a confecção de trajes, deu início à prática do faça você mesmo, estimulando a leitora a costurar sua própria roupa.

Esse processo reforça a relação entre técnica e estilo, sendo o estilo, por exemplo, a silhueta dominante que propunha um tema unificado, ao passo que os detalhes técnicos criavam diversidade (CRANE, 2011). Nesse sentido, ainda que a revista mantivesse a moda do período como tema unificado, os detalhes aplicados à vestimenta pelas mulheres em sua arte de agulhas e bordados, deu novo significado e diversidade ao conceito de elegância vigente. O que se considera não é apenas a moda como cópia, mas a possibilidade de ressignificação da moda, existente na interpretação do modelo, atribuindo a ele características técnicas particulares, tanto utilizando um tecido de sua preferência como adicionando bordados, entre outros debruns, muitas vezes ensinados pelas próprias revistas destinadas à mulher nas décadas de 1950 e 1960, que ao educá-las para lar, contribuíam para o desenvolvimento da história do vestir feminino. Neste sentido, os cursos de corte de costura completavam a educação feminina para a moda. Alguns deles, à distância, como é o caso do Instituto Universal Brasileiro, criado em 1941, que mediante propagandas em jornais e revistas instrumentalizou e forneceu o título de costureira a milhares de mulheres. (MENEZES; SANTOS, 2002).

Deve-se ter em vista que no segundo pós-guerra, encontramos na arte publicitária uma fonte de referências históricas para a inscrição do feminino no espaço urbano. Segundo Scholl (2012, p. 41), a "publicidade, produzida em um dado período temporal e 
direcionada a um determinado grupo social, carrega consigo uma força semântica e estética", enunciando por meio de suas imagens e de seus discursos a cultura e a sociedade de uma época. Partindo dessa perspectiva, a "publicidade veiculada pelas escolas de costura buscava enfatizar o fim nobre e altruístico de preparar as mulheres para o oficio da costura, ressaltando tratar-se das poucas profissões que não desviavam as jovens de sua real finalidade, o lar". (MALERONKA, 2007, p. 77).

Como um exemplo de propagandas, que tinham intuito de convencer as mulheres das vantagens em se estudar o corte e costura a distância, se destacam aquelas produzidas pelo Instituto Universal Brasileiro. Encontradas no Jornal das Moças, assim como em diversas revistas veiculadas no período, estas apresentavam cupons incluídos no fim da página que poderiam ser enviados pelos Correios de forma gratuita para maiores informações sobre o curso. Concomitantemente, como é possível ver na imagem a seguir, os anúncios publicitários da instituição visavam difundir a ideia de "Moças felizes" como aquelas que aprenderam o ofício de corte e costura, apresentando testemunhos de exalunas como incentivadoras das facilidades em se aprender o ofício.

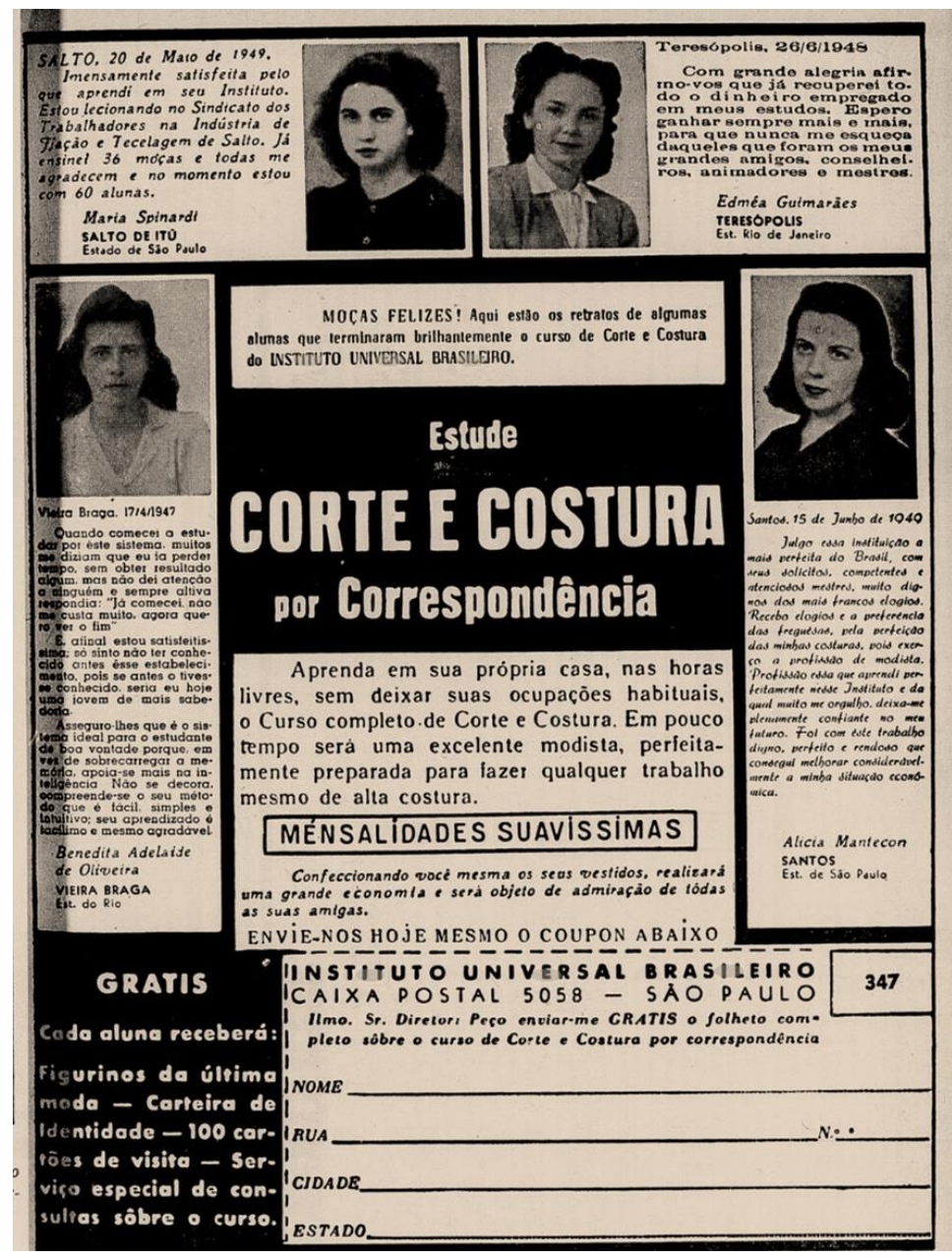

Figura 2 - Anúncio do Instituto Universal Brasileiro no Jornal das Moças ํㅜ 1825, em 8 jun. 1950. Fonte: Biblioteca Nacional Digital Brasil.

Um exemplo desses incentivos presentes no anúncio é o testemunho de Benedita Adelaide de Oliveira de Vieira Braga que escreve: 
Quando comecei a estudar por esse sistema, muitos me diziam que eu ia perder tempo, sem obter resultado algum, mas não dei atenção a ninguém e sempre altiva respondia: "já comecei, não me custa muito caro, agora quero ver o fim". E afinal estou satisfeitíssima, só sinto não ter conhecido antes esse estabelecimento, pois se antes o tivesse conhecido, seria eu hoje uma jovem de mais sabedoria. Asseguro-lhes que é o sistema ideal para o estudante de boa vontade porque, em vez de sobrecarregar a memória, apoia-se mais na inteligência. Não se decora, compreende-se o seu método que é fácil, simples e intuitivo; seu aprendizado é mesmo facílimo e mesmo agradável. (JORNAL DAS MOÇAS, 1950, p. 67).

Como as imagens "publicitárias serviam para reproduzir ideias predominantes no período" (MELO, 2003, p. 21), esse testemunho evidencia o objetivo da instituição em convencer mulheres reais por meio de testemunhos que soassem verdadeiros a elas. Nesse sentido, poderíamos analisar nas palavras de Benedita que para a sociedade da época, resistiam alguns preconceitos com a educação feminina e principalmente com os cursos por correspondência, pois escreve que muitos diziam que era uma perda de tempo, que não se obteria resultado algum. Contudo, mesmo com esses indícios no início do testemunho, ela responde a eles, mas sua resposta mostra que mesmo a mulher era influenciada por esse preconceito. Escreve ela que como já havia começado o curso e que não lhe custava muito, continuaria para ver o fim. Vê-se então, que o preconceito apresentado por ela como vindo de terceiros, é reafirmado pela mesma que não vê inicialmente esse estudo como um aprendizado efetivo, que possa lhe dar resultados. É apenas com o término do curso que Benedita escreve como está satisfeita e como o aprendizado é facílimo e agradável, recomendando-o assim, às outras mulheres.

Unidas aos frequentes depoimentos, os anúncios também difundiam o ideal de feminilidade com frases de efeito como: "Estude EM SUA PRÓPRIA CASA, nas horas livres, sem deixar suas ocupações habituais" ou ainda na mesma página, "Confeccionando seus próprios vestidos, realizará uma grande economia e será objeto de admiração de todas as suas amigas" (JORNAL DAS MOÇAS, 1950, p. 67). Essa propagação de um ensino que possibilitava às mulheres, a continuação de seu papel de donas de casa, mas que a sugeria um novo ofício para a contribuição da renda familiar e ainda que garantia a elegância digna de admiração alheia, fez com que muitas mulheres se interessassem por esse tipo de aprendizagem e buscassem os métodos que ensinavam corte e costura por correspondência, visto que os Correios eram uma forma eficaz de chegar a todos os cantos do Brasil, por mais afastados que fossem.

A busca pelo ensino a distância naquele período era grande, de forma que chegavam ao Instituto cartas diariamente, de pessoas interessadas pelos cursos. Em entrevista para o Museu da Pessoa, publicada online em 06 de novembro de 2013, Luis Fernando Diniz Naso, atual proprietário do Instituto Universal Brasileiro, reafirma a importância do curso de corte e costura para a instituição. Dentre todos os cursos ofertados pelo Instituto, o de corte e costura por correspondência sempre foi o mais procurado. Segundo ele era o curso de maior sucesso, pois mesmo com o passar dos anos, "atualizando todo o curso", ele nunca o deixou de ser. Ainda completa que diferente de outros cursos que tiveram altos e baixos, o curso de corte e costura se manteve por anos e até os dias de hoje, pois "a calça é a mesma [...], não mudou nada", assim "como fazer os moldes é igual".

Outros pontos merecem destaque em relação a procura feminina por esse curso: 0 primeiro diz respeito ao fato que entre os anos 1920 a 1940 houve ampliação do campo da 
moda por meio do trabalho das costureiras e das operárias das indústrias têxteis. Esses aspectos foram abordados por Maleronka (2007) ao mostrar que as transformações na moda em São Paulo caminham pari-passu às atividades das mulheres como costureiras no lar e das operárias fabris, como meios para driblarem a pobreza, as condições sociais e econômicas em que viviam. A contribuição feminina com os ganhos como costureiras domésticas ou com salário de operárias no sustento familiar foram mudanças processadas neste período. Pode-se afirmar então, que a crescente valorização dos ofícios femininos, estimulou "incrivelmente muitas mulheres a aprender a costurar num momento em que a indústria do vestuário já registrava forte expansão, mas ainda não atendia a demanda da população" por esse serviço, o que contribuiu para a "proliferação de escolas de costura que, valendo-se de meios pedagógicos, ministravam esses conhecimentos técnicos". (MALERONKA, 2007, p. 77).

Outra mudança processada no período foi o surgimento do prêt-à-porter (roupas prontas para vestir), que se tornou um divisor na história do vestir e nas maneiras de produção de trajes. Porém, ainda que esta prática de produção pudesse reduzir o ofício das costureiras, com a venda de roupas prontas para vestir,

após 1950, boa parte das roupas produzidas continuava a ser confeccionadas artesanalmente pelas modistas. A confecção mais fina, em razão de tecidos mais caros e delicados, requeria uma costura especializada, com maior qualidade de acabamento à mão, forrações e debruns, além de técnicas de desenho aliadas a conhecimentos das proporções do corpo e extrema criatividade, demandando que experientes modistas estivessem à frente desse trabalho, até porque as modificações na moda ocorriam muito rapidamente. (MALERONKA, 2007, p. 116).

Isso mostra que ainda que as décadas de 1950 e 1960 sejam um período de consideráveis transformações, algumas práticas se mantiveram em contrapartida a essas mudanças. "Cresce também nessa época a demanda por trabalhos considerados femininos" (PINSKY, 2014, p. 17). O corte e costura, como um oficio de conhecimento íntimo entre desenho, tecidos, modelagem e acabamentos, se manteve, pois considerado um trabalho feminino, neste período, o ofício sofreu menor contestação social em relação ao papel das mulheres e o trabalho feminino. Ao aprender corte e costura, às mulheres era possível uma escolha. O ofício poderia ser executado como trabalho doméstico, que mantinha a imagem feminina de "rainha do lar", ou com objetivo de realizar-se profissionalmente fora do espaço privado, que desenhava novas funções como operárias fabris ou costureiras do prêt-à-porter. Como as mulheres eram educadas, pelas escolas, revistas femininas e cursos de corte e costura por correspondência à acompanhar a moda, desde a criação de vestimentas, até que a peça estivesse pronta para vestir, agregando à elas toques de qualidade e criatividade, esses conhecimentos, aliados ao desenvolvimento e a modernização da moda, auxiliaram a inserção feminina em um ambiente social anteriormente masculino, ou seja, o espaço público e do trabalho.

\section{A educação feminina e/para o trabalho feminino}

A importância do ensino para a formação feminina sempre esteve associada à preparação das moças para o casamento, ou em poucos casos a profissões ou ofícios considerados femininos. Nesse período estão presentes duas ideias distintas relacionadas ao ensino de corte e costura. A primeira mantinha a prática como um ofício para o lar e a 
segunda a apresentava como uma profissão. Como ressalta o Método Vogue em suas páginas, há um ponto que não se pode deixar de citar "aquêle em que lembramos a necessidade de todas as moças pobres ou ricas, saberem cortar e costurar, mesmo que depois não queiram seguir a profissão" (CAMPAGNOLLI, 1967, p. 24). Nesse sentido, a arte de cortar e costurar ganha visão profissionalizante, porém não abandona a ideia conservadora de que, mesmo não seguindo a costura como profissão, saber costurar era um ofício indispensável a qualquer mulher na manutenção de sua imagem de feminilidade, independente de qual fosse sua condição financeira.

$\mathrm{Na}$ década de 1960 os movimentos de contestação sociocultural e a causa feminista criticaram de forma bastante contundente as relações que então pautavam as famílias neste período. No Brasil, a educação das mulheres é fato recente e intenso, pois até a década de 1950 "os índices de analfabetismo de mulheres eram vários pontos percentuais maiores que os dos homens" (ROSEMBERG, 2012, p. 334). Foi com a ditadura militar implantada em 1964, que uma perspectiva mais igualitária nos relacionamentos entre homens e mulheres passaria a nortear os valores e práticas familiares, provocando mudanças na socialização das mulheres no Brasil. Paralelamente, a esta perspectiva "tivemos mudanças na economia brasileira que demandava trabalhadores com maior qualificação". (AREND, 2012, p. 77).

Com a demanda por profissionais qualificados, aumenta a necessidade de mulheres no mercado de trabalho fora de casa. Diferente do período após o primeiro pósguerra em que as condições de trabalho e as pressões sociais fizeram com que muitas parassem de trabalhar, principalmente por terem suas profissões associadas à perdição e prostituição, agora algumas mudanças na legislação do país demonstram o início de uma ruptura da tradição patriarcal existente, com o objetivo de atrair mulheres para o trabalho industrial. Sob esse aspecto, "as mulheres só adquiriram o direito de trabalhar sem a autorização do marido em 1943 e apenas com o Estatuto da Mulher Casada (1962) é que se retirou do Código Civil o direito do marido de impedir sua esposa de trabalhar fora do domicílio". (MATOS; BORELLI, 2012, p. 142).

Mesmo no período após a Primeira Guerra Mundial, com o refluxo da participação feminina no setor industrial, as mulheres continuaram a trabalhar. Com o passar do tempo, elas foram ocupando "mais espaço em empregos menos visíveis e estáveis, particularmente no serviço doméstico e no trabalho no domicílio". (MATOS; BORELLI, 2012, p. 134). Nesse sentido,

\footnotetext{
Condicionamentos e necessidades variadas levaram as mulheres a assumir diversas "funções produtivas", abraçando habilmente as possibilidades existentes, ocupando brechas no mundo do trabalho ou tomando para si postos e colocações antes vetados ou inacessíveis. Nesse processo, foram mais facilmente incorporadas ao mercado laboral quando assumiram ocupações para as quais eram consideradas hábeis ou vocacionais (fiar, tecer, costurar, cuidar, servir). (MATOS; BORELLI, 2012, p. 127).
}

O ofício de corte e costura no mercado de trabalho brasileiro então, se reafirma associado a imagem da mulher dócil, subordinada, hábil com trabalhos minuciosos, características ensinadas às meninas como sinônimos de feminilidade, ou seja, características que para o período estavam indissociáveis à ideia de trabalho feminino. $\mathrm{O}$ próprio termo é marcado pela polissemia: alguns confundem "trabalho feminino" com as 
funções domésticas, os cuidados com a família e a casa. Já outros entendem que ele envolve as atividades remuneradas realizadas no próprio domicílio e mesmo a participação das mulheres no mercado de trabalho. Neste último sentido, o trabalho chegou a ser questionado como elemento impeditivo das ditas "funções naturais" das mulheres, as de mãe e esposa (MATOS; BORELLI, 2012, p. 127). É um exemplo da divisão sexual do trabalho que permanecia com força nas mentalidades da sociedade da época.

Partindo dessa perspectiva, os ramos que mais absorviam o trabalho das mulheres eram "aqueles cuja produção anteriormente se fazia nos quadros domésticos, com ensinamentos passados de mãe para filha, ou ainda resultantes da relação de aprendizado com outras mulheres, e eram considerados atribuições femininas" (BOSCHILIA, 1996, p. 26). Nesse sentido as mulheres estiveram presentes no mercado de trabalho principalmente em funções do setor têxtil, de vestuário e de alimentação, ainda que a maioria delas desempenhasse o trabalho dentro do espaço privado. As opções de trabalho feminino domiciliar recorrentes no período, foram abraçadas pelas mulheres, não só por conta das dificuldades de inserção no mercado de trabalho, mas por ser uma opção ao emprego regular, com horário fixo e jornada determinada. $O$ trabalho domiciliar, no sentido de atividades realizadas nas próprias residências para as empresas, oficinas ou intermediários, no regime de pagamento por peça, foi uma prática muito recorrente, pois apesar da remuneração baixa, essas funções permitiam conciliar as atividades de mãe e dona de casa com um trabalho que lhes proporcionava algum rendimento (MATOS; BORELLI, 2012), sem ferir a hombridade do marido.

\begin{abstract}
Mesmo pouco visível (nas sombras) um número expressivo de mulheres trabalhava dessa maneira, particularmente nos chamados trabalhos "de agulha". A qualificação da mão de obra era feita através do processo de socialização e da educação, ou seja, as mulheres utilizavam no trabalho habilidades apreendidas com outras mulheres ao longo de suas vidas. Destreza, rapidez, repetição e precisão eram elementos importantes para a execução de bordados e rendas, costuras, tricô, crochê, manufatura de flores, ornamentos e chapéus, elaboração de enxovais de cama e mesa, lingerie, chinelos e também para a "costura de carregação" de produtos, como sacos de juta para o café e os uniformes fabris. Muitas dessas ocupações eram passadas de geração a geração. (MATOS; BORELLI, 2012, p. 129).
\end{abstract}

O ofício do corte e costura é expressivo quando analisado como força de trabalho feminino, pois foi uma prática que auxiliou de forma significativa a inserção das mulheres no mercado de trabalho. A partir da década de 1960, mudanças comportamentais começaram a alimentar novas expectativas femininas, despertando o desejo de autonomia financeira e de realização profissional. Trabalhar fora de casa era uma opção para a maioria das mulheres, e estava relacionada ao desejo de se realizar profissionalmente (BOSCHILIA, 1996). Nesse sentido, a empregabilidade feminina cresceria de forma sistemática tornando-se constante, intensa e diversificada. (MATOS; BORELLI, 2012, p. 142-143).

Em síntese, mesmo que as duas grandes guerras tenham provocado mudanças, o Brasil as processava vagarosamente, principalmente no que diz respeito à condição das mulheres, que ocorria de forma ainda mais lenta. No Brasil, existem lacunas documentais, quanto às confecções e ao trabalho das costureiras profissionais e domésticas nesse período, que "evidenciam a percepção do valor que a sociedade reservava para as 
atividades tão rotineiramente desenvolvidas pelas mulheres" (MALERONKA, 2007, p. 49). Mesmo com as lacunas documentais e o lento desenvolvimento da presença feminina no espaço público e do trabalho, "indiscutivelmente, uma das maiores transformações dos últimos cem anos foi a presença marcante e evidente das mulheres no mundo do trabalho" (MATOS; BORELLI, 2012, p. 127). Presença essa fortemente influenciada pelos saberes e os fazeres femininos, pelas experiências acumuladas nas lidas com os panos, os tecidos, as linhas, as cores e os desenhos, que ligam as mulheres às novas práticas de significações. São essas "coisas banais" (ROCHE, 2000), mas carregadas de significados e que trazem embutidos conhecimentos femininos em juntar, associar e ressignificar panos e tecidos, que possibilitam a experiência social e cultural das mulheres e da moda, contribuindo de forma significativa para a sua efetiva inserção no mercado de trabalho seja ele no espaço público ou no espaço privado.

\section{Considerações finais}

À guisa de conclusão, retomamos que os adjetivos culturalmente atribuídos a mulher como a fragilidade, a sensibilidade e o temperamento dócil, permitem traçar um todo coerente em que o corte e costura ressurge nesse cenário como um ofício que não interrompe ou denigre essa imagem idealizada da mulher. Os saberes e os fazeres históricos das mulheres com as artes das agulhas, do costurar e do bordar, de usar as cores, de juntar e associar tecidos e rendas, fabricaram uma prática feminina aceitável para a sociedade que via a mulher como braço fraco, que, sendo destinada apenas ao espaço privado, poderia ter um ofício que preservasse sua imagem idealizada de dona de casa de família. Concomitante a isso, aos poucos a presença feminina começa a ser maior no espaço público, das fábricas, com novos postos de trabalho. Assim, analisar o ensino do corte e costura, seja para o espaço público ou privado, indissociável da maneira como as mulheres eram vistas e representavam seu papel na sociedade, revela-se como um poderoso meio de compreensão da história da educação das mulheres no Brasil, de sua inserção no mercado de trabalho e, por conseguinte, de um recorte de elementos sociais e culturais de um dado período histórico, contribuindo assim, para futuros estudos da educação a distância brasileira, do trabalho feminino e da história das mulheres.

\section{Referências}

AREND, Silvia Fávero. Meninas. Trabalho, escola e lazer. In: PINSKY, Carla Bassanezi; PEDRO, Joana Maria (Orgs.). Nova história das mulheres. São Paulo: Contexto, 2012, p. 65-83.

BOSCHILIA, Roseli T. Condições de vida e trabalho: A mulher no espaço fabril curitibano (1940-1960). 1996. Dissertação (Mestrado em História do Brasil) - Universidade Federal do Paraná/UFPR, Programa de Pós-graduação em História, Curitiba, 1996.

CAMPAGNOLLI, Antonio. Método VOGUE: Corte e alta costura. 19 ed. São Paulo: [s.n.], 1967.

CRANE, Diana. Ensaios sobre moda, arte e globalização. Tradução de Camila Fialho. Organização de Maria Lúcia Bueno. São Paulo: Senac, 2011.

JORNAL DAS MOÇAS. n. 1825. Rio de Janeiro, 8 jun. 1950. Biblioteca Nacional Digital Brasil. Disponível em:

<http://memoria.bn.br/DocReader/docreader.aspx?bib=111031_05\&pasta=ano\%20195\&p 
esq=estou\%20satisfeit\%C3\%ADssima>. Acesso em: 20 nov. 2015.

.n. 2313. Rio de Janeiro, 15 out. 1959. Biblioteca Nacional Digital Brasil. Disponível

em:

<http://memoria.bn.br/DocReader/docreader.aspx?bib=111031_05\&pasta=ano\%20195\&p esq=estou\%20satisfeit\%C3\%ADssima>. Acesso em: 20 nov. 2015.

FERREIRA, Amanda Alves. O consumo como simbólico. In: ENCONTRO NACIONAL DE ESTUDOS DO CONSUMO, V, Rio de Janeiro, 2010. Anais... Rio de Janeiro/RJ: 2010.

LOPES, Eliane Marta. Da sagrada missão pedagógica. 1991. Tese (Pós-Doutorado) Universidade Federal de Minas Gerais, Belo Horizonte, 1991.

LUCA, Tânia R. Imprensa feminina. Mulher em revista. In: PINSKY, Carla Bassanezi;

PEDRO, Joana Maria (Orgs.). Nova história das mulheres. São Paulo: Contexto, 2012. p. 447-468.

MALERONKA, Wanda. Fazer roupa virou moda. Um figurino de ocupação da mulher. SP: Estação das letras e cores, 2007.

MATOS, Maria Izilda; BORELLI, Andrea. Trabalho. Espaço feminino no mercado produtivo. In: PINSKY, Carla Bassanezi; PEDRO, Joana Maria (Orgs.). Nova história das mulheres. São Paulo: Contexto, 2012, p. 126-147.

MELO, Lígia, Tureck. A popularização da alta-costura durante as décadas de 1950 e 1960. 2003. Monografia (Curso de História) - Universidade Federal do Paraná/PR, Curitiba, 2003.

MENDONÇA, Carla. Jornalismo feminino, mulher e moda: uma relação histórica. In: ENCONTRO NACIONAL DE HISTÓRIA DA MÍDIA, 9, Porto Alegre, 2013. Anais... Porto Alegre: UFRGS, 2013. Disponível em: <http://www.ufrgs.br/alcar/encontros-nacionais1/9o-encontro-2013/artigos/gt-historia-do-jornalismo/jornalismo-feminino-mulher-e-modauma-relacao-historica>. Acesso em: 20 jan. 2013.

MENEZES, Ebenezer Takuno de; SANTOS, Thais Helena dos. Instituto Universal Brasileiro (verbete). Dicionário Interativo da Educação Brasileira - EducaBrasil. São Paulo: Midiamix Editora, 2002. Disponível em:

<http://www.educabrasil.com.br/eb/dic/dicionario.asp?id=310>. Acesso em: 07 abr. 2014.

MUSEU DA PESSOA. Educação a distância desde os primórdios. Publicado em

06/11/2013. Disponível em: <http://www.museudapessoa.net/_index.php/historia/13515educacao-a-distancia-desde-os-primordios>. Acesso em: 30 abr. 2014.

PERROT, Michelle. As mulheres ou os silêncios da história. Tradução de Viviane Ribeiro. Bauru, SP: Edusc, 2005.

ROCHE, Daniel. História das coisas banais. Nascimento do consumo séc. XVII e XVIII. Tradução de Ana Maria Scherer. RJ: Rocco, 2000.

ROSEMBERG, Fúlvia. Educação. Mulheres educadas e a educação de mulheres. In: PINSKY, Carla Bassanezi. Mulheres dos anos dourados. São Paulo: Contexto, 2012.

PINSKY, Carla Bassanezi; PEDRO, Joana Maria (Orgs.). Nova história das mulheres. São Paulo: Contexto, 2012, p. 65-83.

SANTOS, Liana. Mulheres e revistas: a dimensão educativa dos periódicos femininos Jornal das Moças, Querida e Vida Doméstica nos anos 1950. 2011. 170 f. Dissertação (Mestrado em Educação) - Faculdade de Educação, Universidade do Estado do Rio de Janeiro, Rio de Janeiro, 2011.

SCHOLL, Raphael Castanheira. Memórias (entre)laçadas: mulheres, labores e moda na 
Escola Técnica Sen. Ernesto Dornelles de Porto Alegre/RS (1946-1961). Porto Alegre, RS: PUCRS, 2012.

SCHWARTZMAN, Simon; BOMENY, Helena Maria Bousquet; COSTA, Vanda Maria Ribeiro (Orgs.). Tempos de Capanema. São Paulo: Paz e Terra/Fundação Getúlio Vargas, 2000.

SIMILI, Ivana Guilherme. Educação e produção de moda na Segunda Guerra Mundial. Cadernos Pagu, n. 31, p. 439-469, jul./dez. 2008. Disponível em: <http://www.scielo.br/scielo.php?script=sci_arttext\&pid=S0104-83332008000200019>. Acesso em: 05 maio 2014.

DÉBORA RUSSI FRASQUETE é PhD Candidate na Università luav di Venezia (Itália) no currículo Scienze del Design, temática Design della Moda. Mestre pelo Programa de PósGraduação em História da Universidade Estadual de Maringá (PPH-UEM). Pesquisa na área de Moda e Cultura, como tema as representações na história da moda e do vestir e o ensino das práticas de corte e costura e modelagem.

Endereço: Santa Croce, 597/B - Venezia - Itália.

E-mail: deborafrasquete@gmail.com

IVANA GUILHERME SIMILI é Doutora em História, pela Universidade Estadual Paulista Júlio de Mesquita Filho - Unesp-Assis, professora de Metodologia e Técnica de Pesquisa na Universidade Estadual de Maringá, integrante da linha de pesquisa Fronteiras, Populações e bens culturais do Programa de Pós-Graduação em História (PPH-UEM) e coordenadora do La-Moda, Laboratório de Estudos e Pesquisa em História, moda e cultura (CNPq). Possui diversas publicações na área da história e do vestir.

Endereço: Av. Colombo, 5790 - Bloco H-12 - Sala 16 - 87020-900 - Maringá/PR - Brasil

E-mail: ivanasimili@ig.com.br

Recebido em 21 de novembro de 2015.

Aceito em 01 de março de 2017. 